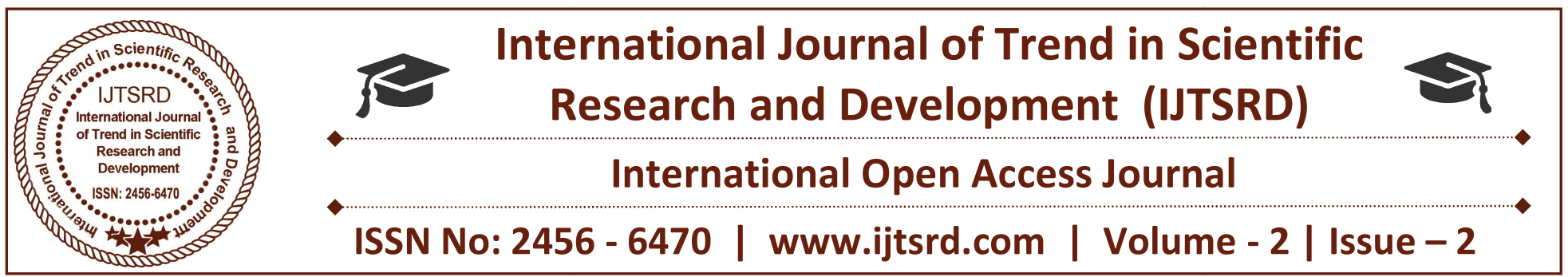

\title{
Educational Leadership: Implications for Quality Management in the Development of Cameroon Higher Education
}

\author{
TamukongNdifor Mariana Ngeche, Ph.D \\ Department of Educational Foundations \\ and Administration, University of Buea, Cameroon
}

\section{ABSTRACT}

Many questions concerning quality of functioning and effectiveness are connected with the management of education as a professional field in educational organizations. Leaders are generally considered as mediators of the social and curriculum contexts of schools for staff, students and parents. They make teaching and learning relevant and appropriately differentiated in compliance with internal and external policy makers' demands and values. Tests presented in the paper deal with the processes of making choices about values and social outcomes of educational leaders. The leadership of Higher Education in Africa has been placed under increasing scrutiny since the 1980 s with the expansion of student numbers, changes in funding for student places, increased marketization and student choice, and continuing globalization and professionalization of the sector. In this macroclimate of change, Higher Education institutions have been required to consider how to develop their leaders and what might be appropriate leadership behaviour to enable adaptation to these new circumstances. When the various paradigms of leadership encountered in the Higher Education sector are compared with established leadership theory and practice, it is possible to identify further intricacies in the development of Higher Education leaders. Further consideration of practicalities within Higher Education identifies whether competence frameworks might assist in leadership development. An examination of a recently developed comprehensive framework of leadership capabilities applied in an alternative sector leads to an evaluation as to whether the same constructs apply to the demands placed upon leaders in Higher Education. Analysis demonstrates that, with minor changes in terminology, the constructs remain appropriate and valid. The definitions of activities and behaviours offer insight into how Higher Education leaders particularly in Cameroon could be developed and therefore form a potential framework of leadership capabilities for Higher Education. This conceptual paper therefore has leadership and educational management bearing within the context of Cameroon.

Keywords; Educational Leadership, Management Development

\section{Introduction}

The construction of schools as organizations and communities is carried out by all stakeholders within the educational community, be they authorities, administrative staff, support staff, teachers, parents of students, students, persons from socio-professional circles, regional and local authorities (Law No. 98/004). Some stakeholders have more access to power to influence the shaping of these entities. The more powerful are usually the formally designated senior leaders of a school, who enact a variety of policies in specific socio-economic and macro-policy contexts to construct preferred organizational cultures, teaching and learning practices. They create, organize, manage, monitor and resolve value conflicts of many different people which reflect the view of the world constructed by each stakeholder (Owens, 2001). Formal leadership is carried out at many levels in a school from senior leaders (deputies) to middle leaders who manage academic and pastoral departments as well as administrative services such as 
the school office or the school site. First-line leaders or supervisors act in certain socially defined ways in certain circumstances (lessons, playgrounds). Their supervisory role is based on their hierarchical position in school. Informal leaders exist in school, department or classroom level as well as in extra-curricular activities. Their influence is based more on their personal and work-related skills and knowledge and their alliances with other people inside and outside the school than on their formal position in a school. They therefore include students and teachers (Busher, 2006). As school systems developed into large bureaucratic organizations, school leadership is in contestably primordial for educational development. Lending credence to the position, a high degree of association has been established between educational status of an individual as well as that of a nation, and measures of development. In particular, it is the conviction of international organizations including United Nations that education plays an especially important role in addressing health disparities and in mediating the "income effect" on equalities (Carr, 2004:16). Hence, education appears to be a magic wand necessary for peace and security, for the rule of law and justice to prevail, poverty alleviation, disease control and obliteration, energy production and sustainability, political stability and international cooperation (Fajonyomi, 2007). For emphasis, Gills (1999) likened the relationship between education and development to a switch, which turns on light that brightens the darkness of poverty and enlightens the lives of the people. If education in general is recognized as a central element to development, higher education (HE), also known as tertiary education, or post-secondary education, cannot cause less effect. The 1998 World Conference in Higher Education (WCHE) affirmed that $\mathrm{HE}$ has unprecedented role in the present day society as a pillar to endogenous capacity building, the consolidation of human rights, sustainable democracy and peace in the context of justice. In the same vein, Gills (1999) reiterated that HE has never been as important to the future of the world, as it is right now. If it cannot guarantee rapid economic development, sustained progress is impossible without it.

Higher education (HE) in Cameroon is steered by policies and conditions, which overlap at the national and international levels. As an active member of the international community, Cameroon is a signatory of many international cooperation and solidarity conventions, including those related to education. As a poor and therefore, borrowing and aids dependent country, its HE has been subjected to prescriptions, regulations and re-regulations from international development agencies. These include the World Bank, the United Nations Development Programme (UNDP), the International Monetary Fund (IMF) and the African Development Bank (ADB), which have been significant in shaping Cameroonian HE in recent years. As implied earlier, the financing of $\mathrm{HE}$ in Cameroon as most of Africa, was for about two decades relegated to the background in favour of other sectors and educational subsectors based on prescriptions from international institutions. However, the recent changes being observed in the current study would be seen partially to be attributed to the recent rediscovery of the importance of higher education as a driver of economic growth at the various levels.

\section{Contextualizing the background}

The current university system in Cameroon can be traced from the transformation of the National Institute for University Studies to the Federal University of Cameroon, which began in 1962 with 529 students (Njeuma et al. 1999). Until independence in 1960, most Cameroonians pursued HE abroad, especially in Germany, France and Britain during their respective annexation and colonial eras and based on the bilateral frameworks they established. Other frameworks also existed within colonial, ex-colonial, socio-linguistic and cultural networks, which made it possible for Cameroonians to receive higher education in other African countries and even continents within the networks. These were the cases of Anglophone and other earlier Francophone universities, which hosted Cameroonians for higher education. In terms of structure, the Cameroonian HE system has undergone through a drastic and dramatic structural change (as marked by the 1993 reforms), from a combination of an earlier dual and stratified (elitist) system (Doh 2007) to a (massified) open access system. This drastic or dramatic structural adjustment was a serious deviation from the colonial conception of the higher education system in Cameroon. Earlier, there was only one multi-faculty and comprehensive university in the liberal arts, science and social sciences called the Federal University, which was renamed the University of Yaoundé. The HE system instead developed through specialized faculty like establishments called centers, schools and institutes, which were implicitly stratified, and elitist with highly 
selective entry conditions. Although this type of French system of stratification which was adopted in Cameroon may have been less clear than the American or Anglo-Saxon systems, the establishments were however distinctive in terms of their civil service and strong professional and technical orientations (Ben-David 1977). Again, although some of the previous faculty-like establishments in Cameroon could be both first and second tier institutions offering the respective degrees, they were mostly teaching and applied institutions without postgraduate and research status. The Minister of higher education is the Chancellor of all Cameroon's State universities. Pro-Chancellors and rectors are appointed by presidential decrees to manage the universities.

Almost thirty years after the inception of the HE system in Cameroon, it had become clear that a system characterized by professional and technical civil service-oriented and elitist institutions could not absorb the mass wanting to get into higher education. The lone University of Yaoundé itself had a serious capacity problem. For instance, by on a campus designed for 5000 students (Njeuma et al. 1999). This was coupled with unemployment since the education of the main university was in classical liberal programmes and less employment or market relevant compared to those of the specialized establishments. In addition, those specialized professional and technical institutions seemed to receive more attention from an immediate development perspective and less in terms of the expansion that might take place in the main university. The government had to take serious measures through the 1993 reforms among which was the creation of five full-fledged universities to add to the University of Yaoundé. These new universities were developed from some of the existing university centers. For the sake of coordination, the professional and technical HE establishments were all brought into the main university system and granted academic and postgraduate research status to facilitate mobility between non-specialized and specialized establishments and to increase their research productivity. With regard to the traditional classical programmes of the main university, the government through the 1993 reforms engaged in professionalization. Today the HE system in Cameroon presents a unitary structure of eight main institutions: the Universities of Yaoundé I, Buea, Yaoundé II, Dschang, Ngaoundere, Douala and Maroua and Bamenda (the first six universities having been born from the 1993 reforms and the last two established in 2008 and 2010 respectively). In addition to these eight universities, there are two virtual universities, one of which is for the CEMAC sub-region and a centre for telemedicine (SUP INFOS 2010, No. 13, 18).

The trends over the years indicate that the annual average increase in student numbers is about 20 per cent. For instance, in the 2002-2003 academic years, the student numbers stood at 74,105. In 2006-2007 it was about 130,000 students and in 2010 about 210.000 (2004, 2007 Statistical Yearbooks; SUP INFOS 2010a). These increases place the policymakers in difficulties in terms of planning, funding and infrastructure with implications on quality. The languages of instruction in the Cameroonian HE system are French and English. Two of the eight universities (Buea and Bamenda) are conceived in the Anglo-Saxon tradition and are English-speaking monolingual universities. The University of Ngaoundere is a Francophone, Frenchspeaking monolingual university conceived in the respective tradition. Meanwhile the mother institution, University of Yaoundé 1 officially remains a bilingual (French and English-speaking) university. The other four universities are bilingual with a dominant Francophone orientation. As a matter of expertise, lectures can still be delivered in the teachers' first official language (English) in the four Frenchspeaking universities.

There has been a growing interest in the role of leaders within Higher Education (HE) institutions in recent years, driven both by the influence of $\mathrm{HE}$ institutions in developing learners who later develop as leaders in wider society, and by the changing shape of HE leadership itself in the face of global challenges in the sector. Several contextual shifts have occurred within the Higher Education sector in recent decades, particularly globalization. of the market and internationalization of institutions, development of for-profit private institutions, cutbacks in public funding and increased cross-border academic mobility (Gibbons, 1998; Middlehurst, 1999; Schofer\& Meyer, 2005; Altbach, 2011). Since the 1990s the leadership approach encountered in Africa in general and Cameroon in particular Higher Education institutions has been placed under increasing scrutiny with the need to adapt to a huge expansion in student numbers and the development of a fee-paying culture (Deem, 1998) which has changed expectations to a more 
outward-facing student focused approach, largely at odds with the traditional inward-looking collegial approach (Hides, \& Casey, 2001). This change has driven a move in Cameroon institutions from "administration" (keeping things ticking over) to a pervading "management culture" ever since (Clegg \&McAuley, 2005), with comparable change in management functions of African Universities observed since the 1980s (Amey, 2006).

Every attribute of an analysis system illustrates the specific management and leadership in which the process of decision-making is conducted. Directed rigidity is the consequence of the curriculum rigidity. Rigidity is in direct correlation to the old fashioned but still characteristic concept of education by which the educational process needs to be organized and controlled; it does not come out of this process. The educational sector in Cameroon has not succeeded in one of its basic tasks, enabling and stimulating users' personal growth (pupils, students, and teachers). In 2001, the Organization for Economic Cooperation and Development OECD analyzed the situation in Cameroon schools and found that the Cameroon school system is too centralized in determining and implementing the curriculum. On the other hand, the evaluation of activities is not centralized. Complete decentralization is present in the field of evaluation of work quality. It seems that playing an important part in a teaching role is very far from leaders' 'main' function which is leadership as a part of management. The primary function of leaders is to manage and lead the organization (regardless of the level of work, small group, class, parallel class, school, municipal district, a nongovernmental organization, bank, ministry...) towards meeting the goals of the organization. Leadership differs in the content and purpose of leadership, but also in the way of leadership.

A close look at the goals of $\mathrm{HE}$, as highlighted in a nation's law/policy (Law No. 005 of 16 April 2001 to Guide Higher Education) document like that of Cameroon, provides a pointer to its contributions to development. For instance, the goals of $\mathrm{HE}$ as specified in the Cameroon National Policy on Education ((Law No. 005 of 16 April 2001 to Guide Higher Education) reaffirms that the basic mission of the higher education realm stipulated in article 2 , shall have the following goals:

- The quest for excellence in all domains of knowledge
- The promotion of science, culture and social progress

- Social promotion, with the participation of competent national bodies and socio-professional circles, especially as concerns the drawing-up of programmes as well as the organization of theoretical courses, practical's and internships

- Assistance to development activities

- The training and further training of senior staff

- The deepening of ethics and national consciousness

- The promotion of democracy and the development of a democratic culture

- The promotion of bilingualism; In this end, the higher education realm shall

- Ensure that higher education or secondary school students are informed of the organization of studies as well as the professional openings and reorientation possibilities from one training course to another

- the initial and continuous training of higher education students and other learners in the intellectual, physical and moral domains

- Organize the training of trainers and researchers

- Train intermediate and senior staff for scientific and technical domains

- Ease innovation as well as individual and collective creativity in the domain of arts, letters, science and techniques

- Promote bilingualism, culture and national languages

- Contribute to the strengthening of national consciousness

- Contribute to the promotion of respect for the law by disseminating a culture of respect for justice, human rights and freedom

- Participate in the elimination of all forms of discrimination and shall encourage the promotion of peace and dialogue

- Contribute, within the national and international scientific and cultural community, to discussions, the advancement of research and cultural exchange

- Contribute to the mixing of peoples and national integration

- Participate to the development and strengthening of gender equality

- Contribute to the emergence of a democratic culture, as well as a culture of peace, development and tolerance. 
- CHAPTER II of the above law focused on the Elaboration, Implementation and Monitoring of the Higher Education Policy.

Unfortunately, without a need for a soothsayer and as recognized by Dais (1998), Adedipe (2005) and Martin (2007) "there are challenges clogging the wheel of HE institutions in fulfilling their multiple missions of improving the quality of their provision of education, increasing their efficiency and in demonstrating their contribution to society". These challenges, though in exhaustive, include:

- Fiscal and financial debase resulting from nation's structural adjustment programme.

- Fiscal policy, especially currency devaluation in many developing countries.

- Substantial increase in the demand for higher education.

- Increased pressure on existing inadequate infrastructures and utilities.

- Poor funding.

- Government instability.

- Uncritical about supervision and control, system including selection of vice-chancellor.

- Inconsistent government policy concerning institutional administration.

- Institutional Crises.

The identified challenges are recurring, particularly for the increasing demand for HE. What is worrisome is the incapability of the financial and administrative machinery to respond to the growing demand for $\mathrm{HE}$ especially in developing countries (Martin, 2007) and its untold effect on the quality of graduate from higher education institutions. Intuitive and empirical reports on the graduates of HE institutions in Cameroon are disturbing. In recent times, Cameroonians are worried about the state of HE in the country. For example, there had been complaints by employers across board that Cameroonian HE graduates are poorly prepared for the workplace. Industries, commerce and public sector have to retrain the graduates to fit into the work requirements of these various places.

\section{Conceptual Review}

\section{Leadershipand educational management Leadership}

Fullan (2001) and Hodgkinson (1991) consider leadership to be essentially a moral art facing postholders constantly with moral dilemmas about which decisions to take since taking one set of decisions is likely to exclude others, privileging some people's needs over others. Macbeath and MacDonald (2000) suggest that ethical decision-making which guarantees transparency and accountability of the needs of other members of a school community, is primordial to how school leaders use power successfully since it promotes social cohesion and creates more accessible teaching and learning opportunities for all students. Leaders should develop school cultures and departmental sub-cultures that foster positive relationships based on shared values that can help people to construct a sense of community (Sergiovanni 1992, 2001). A key element of such cultures is that of trust between members. Trust promotes personal and work-related growth of staff, students and parents.

Muijs and Harris (2003) developed the concept of teacher leaders, as people who have a major part of their work based in the classroom but seek to work collectively with their colleagues outside it to shape policy. Durant (2003) limits the notion of teacher leadership to people holding non-promoted posts in schools but who take a lead in decision making in a school beyond the doors of their classrooms. From this perspective, Harrison (1994) holds that people not systems are the centers of knowing and the constructors of meaning. Institutions and communities like schools are built through processes of debate, dialogue and interaction between individuals and collectivities, such as departments or groups of students or occasionally groups of parents. Leaders at all levels in schools, as in other communities in society try to circumvent the dilemmas and social tensions they generate by creating rational processes and rules for taking decisions which legitimate their decisions. Control of the rules of an organizational system is a means of exerting influence or sustaining dominance by leaders. Decision-making on the teaching and learning process in schools can be perceived as political and negotiative interactions that are invested with flows of power through the people taking part in them. Gronn (2000) suggests that effective school organization, will lead to genuine distribution of leadership that will promote the personal and work-related growth of staff, students and parents.

A central element in many definitions of leadership is that there is a process of influence. Most definitions of leadership reflect the assumption that it involves a 
social influence process whereby intentional influence is exerted by one person [or group] over other people [or groups] to structure the activities and relationships in a group or organisation. (Yukl 2002: 3) Leadership may be understood as 'influence' but this notion is neutral in that it does not explain or recommend what goals or actions should be sought through this process. However, certain alternative constructs of leadership focus on the need for leadership to be grounded in firm personal and professional values.

Wasserberg (2000: 158), for example, claims that 'the primary role of any leader [is] the unification of people around key values'. Day et al.'s (2001) research in 12 'effective' schools in England and Wales concludes that 'good leaders are informed by and communicate clear sets of personal and educational values which represent their moral purposes for the school' (p. 53). Vision is increasingly regarded as an essential component of effective leadership. Beare et al. (1992) draw on the work of Bennis and Nanus (1985) to articulate ten 'emerging generalizations' about leadership, four of which relate directly to vision:

- Outstanding leaders have a vision for their organizations.

- Vision must be communicated in a way, which secures commitment among members of the organization.

- Communication of vision requires communication of meaning.

- Attention should be given to institutionalizing vision if leadership is to be successful.

These generalizations are essentially normative views about the centrality of vision for effective leadership. There is a high level of support for the notion of visionary leadership but Foreman's (1998) review of the concept shows that it remains highly problematic. Kouzes and Posner (1996) say that inspiring a shared vision is the leadership practice with which [heads] felt most uncomfortable', while Fullan (1992) adds that 'vision building is a highly sophisticated dynamic process which few organizations can sustain'. It is evident that the articulation of a clear vision has the potential to develop schools but the empirical evidence of its effectiveness remains mixed. A wider concern relates to whether school leaders are able to develop a specific vision for their schools, given government influence on many aspects of curriculum and management.

\section{Educational Management}

Bolam (1999) defines educational management as 'an executive function for carrying out agreed policy'. He differentiates management from educational leadership which has 'at its core the responsibility for policy formulation and, where appropriate, organizational transformation' (p. 194). Writing from an Indian perspective, Sapre (2002) states that 'management is a set of activities directed towards efficient and effective utilization of organizational resources in order to achieve organizational goals'.Glatter (1979: 16) argues that management studies are concerned with 'the internal operation of educational institutions, and also with their relationships with their environment, that is, the communities in which they are set, and with the governing bodies to which they are formally responsible'. In other words, managers in schools and colleges have to engage with both internal and external audiences in leading their institutions. This statement delineates the boundaries of educational management but leaves open questions about the nature of the subject. The present author has argued consistently (for example, Bush 2003) that educational management has to be centrally concerned with the purpose or aims of education. These purposes or goals provide the crucial sense of direction, which should underpin the management of educational institutions. Management is directed at the achievement of certain educational objectives. Unless this link between purpose and management is clear and close, there is a danger of 'managerialism', 'a stress on procedures at the expense of educational purpose and values' (Bush 1999). 'Management possesses no superordinate goals or values of its own. The pursuit of efficiency may be the mission statement of management - but this is efficiency in the achievement of objectives which others define' (Newman and Clarke 1994). Managing towards the achievement of educational aims is vital but these must be purposes agreed by the school and its community. If managers simply focus on implementing external initiatives, they risk becoming 'managerialist'. Successful management requires a clear link between aims, strategy and operational management.

\section{Distinguishing Educational Leadership And Management Development}

The concepts of leadership and management overlap. Cuban (1988) provides one of the clearest distinctions 
between leadership and management. He links leadership with change, while management is seen as a maintenance activity. He also stresses the importance of both dimensions of organizational activity: By leadership, I mean influencing others' actions in achieving desirable ends. Leaders are people who shape the goals, motivations, and actions of others. Frequently they initiate change to reach existing and new goals ... Leadership ... takes ... much ingenuity, energy and skill. Managing is maintaining efficiently and effectively current organizational arrangements. While managing well often exhibits leadership skills, the overall function is toward maintenance rather than change. I prize both managing and leading and attach no special value to either since different settings and times call for varied responses.

Day et al.'s (2001) study of 12 'effective' schools leads to the discussion of several dilemmas in school leadership. One of these relates to management, which is linked to systems and 'paper', and leadership, which is perceived to be about the development of people. Bush (1998, 2003) links leadership to values or purpose while management relates to implementation or technical issues. Leadership and management need to be given equal prominence if schools and colleges are to operate effectively and achieve their objectives. While a clear vision may be essential to establish the nature and direction of change, it is equally important to ensure that innovations are implemented efficiently and that the school's residual functions are carried out effectively while certain elements are undergoing change. Educational institutions operate within a legislative framework set down by national, provincial or state parliaments. One of the key aspects of such a framework is the degree of decentralization in the educational system. Highly centralized systems tend to be bureaucratic and to allow little discretion to schools and local communities. Decentralized systems devolve significant powers to subordinate levels. Where such powers are devolved to the institutional level, we may speak of 'self-management'.

\section{CONTEXTUAL MODELING OF THE STUDY}

The leadership and management challenges experienced in Higher Education (HE) over recent decades have led to the emergence of various leadership approaches within the sector and can be observed in many HE institutions across all regions, whether research-led, teaching-led, large or small, specialized or multi-faculty.

\section{Hierarchical Models}

One of the most typical approaches encountered in $\mathrm{HE}$ institutions is the authority and power model associated with hierarchy (Astin\&Astin, 2000). Teacher-centered approaches tend to equate to this top-down, autocratic view of leadership (Amey, 2006). The negative aspects arising from this type of command-and-control approach have been previously highlighted. Furthermore, in higher education, the development of learning communities, encouraging social change or inspiring in students a sense of being part of a global society, demands a much more adaptive and open sense of leadership, which is contrary to the hierarchical command-and-control mind-set. Academic leaders need to dispense with "positional" authority, normally associated with command-and-control leadership, in order to enable more transformational learning approaches to be undertaken by students (Amey, 2006). It has also been suggested that a command-and-control approach is particularly unsuitable and counterproductive when managing academic colleagues (Goffee\& Jones, 2009).

\section{Individualistic Models}

Individualistic leadership is based on personal status and professional recognition, is usually encountered within academic faculty positions, and has been identified in American colleges as a key reason for driving the higher value of research versus teaching (Astin\&Astin, 2000). The balancing of teaching and research commitments is a contentious theme in many HE institutions. The negative effect of individualistic leadership is that it makes collaboration more difficult, since competition is seen as more rewarding. Additionally the individualistic paradigm is biased against some minorities, particularly women, who may take career breaks, which affect their accumulation of research achievements. This is a particular issue in science and technology where the progression of women is notably negatively affected, such that in the UK specific national initiatives aim to develop women in science, technology, engineering, math's and medicine (Garforth\& Kerr, 2009; ECU, 2015). Similar debates around gender and ethnicity continue in institutions in the USA and Europe (Etzkowitz et al., 1994; Amey, 2006; D'Amico, Vermigli, \&Canetto, 2011). 


\section{Collegial Models}

Collegiality is a term used in two distinct ways: sometimes it refers to a system of governance driven by consensual decision making and on other occasions, it refers to mutual supportiveness among staff (Bryman, 2007). Whilst the latter peer-support is valued in academic communities (Bryman, 2007), the former is the usual structural outcome (i.e. a committee or bureaucratic-based approach) which paradoxically drives the general dislike in academic circles of "administrative" work (Astin\&Astin, 2000). Clegg and McAuley (2005) assimilate these by defining the Collegial concept as one where academics work together whilst retaining their individual interests, eschewing any attempt to be actively managed, so that individuals are left to do their own thing as long as traditional rituals and duties are observed. Essentially the collegial approach is pursued for the benefit of the community itself, not users or external demands placed upon that community (such as expectations of the government, students, industry, or funding bodies) and this raises difficulties for the institution itself.

\section{Collaborative Models}

Developments in leadership thinking over the past 30 years have emphasized collaborative approaches (Heifetz \& Laurie, 1997; Bennis, 1999, 2009; Kouzes \& Posner 2007) yet Higher Education has been relatively slow to pick up the importance of this principle, largely due to the traditional functional specialism engendered in faculty structures. Over the last 20 years collaboration appeared to be initiated, expected and driven by research funders, rather than institutions themselves (Defazio, Lockett, \& Wright, 2009). Within academic roles successful leaders are increasingly seen to be those more able to develop collaborative partnerships and to establish networks in a non-hierarchical manner (Amey, 2006), whilst retaining accountability and evidence-based approaches which demonstrate what does, and does not work. The traditional model where senior professors elected from their own ranks for short terms of office is perhaps no longer practical in the light of the now myriad skills demanded in an effective university leader (Altbach, 2011).

Transformative Models Transformational leadership models have tended to dominate the understanding of leadership within the HE sector (Astin\&Astin, 2000) and tend to resonate positively with their apparent foundation upon human interactions, which matches the demands of faculty and campus-based leadership roles. The expectation of "emotional intelligence" in leadership (Goleman, 1997) is attractive; HE institutions are essentially in the business of human interaction. At an academic level, the "learnercentered" approach to education matches the adaptive concepts of transformational leadership (Amey, 2006). Additionally, the transformational approach is also perceived to match with the challenges of a changing sector (globalization and user-driven demands) and is a leadership approach, which will better enable the creative solutions, which are needed to meet those challenges. Certainly, the role of $\mathrm{HE}$ institution leaders as change agents has become increasingly important (Amey, 2006).

\section{Assimilating Models of Leadership for Higher Education}

Fortunately our understanding of leadership in other sectors can offer assistance in assimilating which principles of leadership can be applied in the HE context, and how. An effective leader needs to apply both transformational and transactional leadership approaches (Bass \&Avolio, 1993) depending on the different individuals and tasks being undertaken at various points in time. The practical challenge for the leader is to be able to perceive which elements to manage within the context of each particular situation (e.g. people, task, team, and other contextual information). Kouzes and Posner (2007) offer one of the more heavily scrutinized frameworks of leadership. Their five practices of Exemplary Leadership can be compared to existing models devised within the HE sector.

The comparison illustrates that the breadth of leadership challenge in HE is congruent with Kouzes and Posner's (2007) model, but the detail within each element of the HE models is less clearly defined. For example, how a shared vision is developed and implemented in HE is less well defined even within the well-bounded confines of an academic department (Bryman, 2007) than is understood in general leadership theory and practice. Perhaps more starkly, the ways in which HE leaders can influence and seek improvements and innovation is much less well defined in current HE frameworks.

Similarly, how HE institutions encourage and recognize efforts is poorly understood aside from traditional academic promotion pathways. Leadership 
competency frameworks, where available, can be helpful guides, but if used require caution (Bryman, 2007). For example, knowing that a leader has to cultivate personal integrity may be useful, but how one goes about establishing and maintaining personal integrity is a different matter.

Also in some models, the aspects of leadership appear to clash, such as the balance between developing one's own research credibility and the ability to also manage a department (Bryman, 2007); aside from potential goal displacement, time constraints alone may work one priority against the other. In addition, a competence framework needs to appreciate the contextual notion of leadership (Tannenbaum\& Schmidt, 1973). For example, would a list of effective leadership behaviours remain valid across the diverse contexts within which university leaders are likely to find themselves (Bryman, 2007) such as in diverse professional service, student-support, academic or senior executive roles? Does leadership behaviour transcend the roles of senior executives and vicechancellors, departmental or school leaders and other professional positions? How would a leadership framework accommodate sector-typical anomalies such as rotating roles (e.g. 3 year posts) for people in academic leadership positions (Bryman, 2007)? A further risk is that in following a set of competencies a leader will focus on "doing leadership" rather than ensuring that effective work is done (Seddon, 2003).

This means that a list of effective leadership practices must itself focus the leader on the appropriate purpose of their role. Kouzes and Posner's (2007) framework attempts this by bringing the importance of shared vision, principles and clear goals to the forefront. However, it is strongly argued by many leadership commentators that a focus on organisational purpose is the primary test of good leadership (Peters \& Waterman, 1982; Bennis, 1999; Scholtes, 1998; Hamel, 2009). A focus on purpose is the foundation of Systems Thinking which is rarely encountered in HE leadership yet which is extensively discussed in management literature (Deming 1982; Senge, 1990; Womack \& Jones, 1996; Seddon, 2003). Understanding the organization as a system is important since a suitable leadership approach is unlikely to emerge in the natural order of things. For example, if collaboration is required, then the institution must be seen to value that activity (Astin\&Astin, 2000); only then will leaders be inclined to pursue collaborative work. If the general system (rules, measures of performance, promotion criteria, goals, procedures) suggests a different set of priorities, then a different outcome will emerge (Seddon, 2003). Put a good performer in a bad system and the system wins every time (Rummler\& Bache, 1995)

\section{POLICY IMPLICATIONS FOR HIGHER EDUCATION DEVELOPMENT}

This conceptual and policy paper, if not for anything, should pricked everyone to research assiduously into the leadership qualities that would really make a difference in higher education institutional outcomes. At the same time, there would be need to re-define more specifically, outcomes which have knitted to the factor of leadership to outcome to avoid overestimation or underestimation of the contributions of leadership factor. If done, this will facilitate the development of a standard template useful in ascertaining effectiveness or otherwise of an $\mathrm{HE}$ institutional leader. Such research findings will precisely suggest variables that should be expunged or retained, in the template currently in use, especially in developing countries like Cameroon where extraneous factors are often introduced to the process of $\mathrm{HE}$ leadership selection.

The developed template could also serve as basis for performance evaluation of the leader, a culture that appeared strange to the universities in most developing countries particular in Cameroon as highlighted through reviews. In other words, every university in the developing countries should imbibe the culture of self-evaluation - inputs, process, programmes and outcomes, a common exercise in the developed countries (Breuder's report in 2007 for example). Such regular evaluation exercise will make the HE leaders more accountable and responsible than hitherto.

On the issue of assessing the personality and behavioural aspects of would-be HE leaders, it is clear that reliance on referees' reports, assessment of curriculum vitae and or interview is not sufficient. The time is ripe that aspiring HE leaders should be tested in such areas as intelligence, interest and personality. It is proven that "the most accurate predictor of managerial successes is the clinically oriented assessment" (Flippo, 1980). As such battery of selection tests should be developed. 
The bottom-line for a formidable quality assurance is resources. Leadership should think of attracting resources outside the university by using qualified professionals and workers in private and public sectors of the economy as resource persons or associate lecturers. Such effort could further strengthen the relationship between town and gown. In addition, fund provided should be invested wisely and prudently to win the confidence of the provider.

Finally, attention has been drawn to the intrinsic value of institutional leadership in HE quality control. It is suggestive therefore, for cost-effectiveness, to strengthen leadership at this level, through capacity building arrangement.

\section{CONCLUSION}

Current Cameroon frameworks of leadership for the Higher Education sector do not encompass all of the behaviours expressed in established leadership literature. Higher Education leaders need a combination of leadership and management competencies in order to address the leadership and, managerial challenges faced in the sector; separation of these facets is counterproductive and will not address the negative impact of managerialism perceived within institutions. The framework developed in this analysis offers a suitable range of approaches for leaders in HE. Within a changing world, an effective leader must be both student and teacher (Kotter, 1996): always hungry to learn more about how to enthuse, engage and empower those who follow. For staff in academic positions, becoming a "learner" may be uncomfortable, so these individuals should be encouraged, through the active, visible and credible example of seniors and peers, to appreciate the benefits and necessity of personal leadership development. On a light note, one can imagine that if the sectors in Cameroon were to be classified according to government priorities in general, funding and direct relationship to poverty reduction, the higher education sector that is represented by a ministry and universities would hardly feature among the first score of priority sectors. Worth citing are a few of the thirty-seven ministries in Cameroon with which HE competes for public funding as a subsector besides competing with three other subsectors in the education sector. Paradoxically, it will be shown in this study that HE is the most strategic sector that can transform all the sectors and thus give Cameroon, from a national perspective, a new development facelift. Higher education is the only sector that can comparably claim to be second only to the state government (Fuller 2005). Although it is simply an educational subsector, it is paradoxically the only sector that is omnipotent and omnipresent in the development of all the other sectors. It is a passé par tout. It fits and intervenes to develop every sector. The example of the known multiple roles of the sector are that higher education has been traditionally assigned to produce human capital for national development, widen access, provide citizen education, drive national social inclusion policies, develop the agricultural sector, mining, health, women's emancipation and gender equality, national defense, the lower educational cycles and many other sectors through embodied knowledge, research, training and capacity-building. Globalization and changes in the structure of economies have introduced new pressures for it to provide quality education and research for innovation and competitiveness of nations and at the same time, respond to its immediate regional development needs. The connection of HE to related sectors in fostering research, science and technology and industrial innovations which have higher potentials to drive knowledge based economic development and society remains as direct as possible.

\section{REFERENCES}

1. Fonkeng, G. E. (2007). The History of Education in Cameroon: 1884-2004. Queenstown Lampester, New York: The Edwin Mellen Press.

2. Mvesso, A. (2005). Pour une nouvelle education au Cameroun; Les fondementsd'uneecolecitoyen du developpement. Yaounde: Presses Universitaire de Yaounde.

3. Adedipe, N.O. (2005), The Changing Roles of University Councils. National Universities Commission, Abuja-Nigeria.

4. Aderonmu, O. and Aina, O. (1986), Managing the Nigerian Education Enterprise. John West Publications, Ikeja-Lagos.

5. Akinkugbe, O. (2005), "University education in Nigeria: Pain, paradox, panacea". Jibril, M. (ed) Perspectives and reflections in Nigerian Higher Education, Spectrum, Ibadan.

6. Brown, J. (2004), "Leading through followers", Organisational Leadership. Date retrieved. 27-1007 
7. Burns, J.M. (1978), Leadership. Harper \& Row, New York.

8. Obanya, Pai (1981), Evaluation on Modern Language. Teaching Institute of Education, Ibadan. Obanya, Pai (2006), "African School Curriculum as a Front on Which to Widen Access to Education".

9. Adair, J. (1979). Action-Centred Leadership. Aldershot, United Kingdom:

10. Gower. Alexander, F. K. (2000). The Changing Face of Accountability: Monitoring and Assessing Institutional Performance in Higher Education. The Journal of Higher Education, 71, 411-431.

11. Altbach (2011). The Past, Present, and Future of the Research University. In P. G.

12. Altbach, \& J. Salmi, (Eds.), The Road to Academic Excellence (pp. 11-32). Washington DC: The World Bank.

13. Amey, M. J. (2006). Leadership in Higher Education, Change: The Magazine of Higher Learning, 38, 55-58.

14. Astin, A. W., \&Astin, H. S. (2000). Leadership Reconsidered: Engaging Higher Education in Social Change.

15. Battle Creek, MI: W.K. Kellogg Foundation. Bass, B. M. (1997). Does the TransactionalTransformational Leadership Paradigm Transcend Organizational and National boundaries? American Psychologist, 52, 130-139.

16. Bass, B. M., \&Avolio, B. J. (1993). Transformational Leadership and Organizational Culture. Public Administration Quarterly, 17, 112121.

17. Tchombe, T. M. (2001). Structural Reforms in Education in Cameroon. Unpublished policy paper.

18. SUP INFOS. (2010a). A Bilingual Quarter Review of Higher Education in Cameroon. No. 13 ,

19. SUP INFOS. (2010b). A Bilingual Quarter Review of Higher Education in Cameroon. No. 14, MINESUP Yaoundé, Cameroon.

20. Njeuma, D. L (2003). Cameroon. In D. Teferra\& P. G. Altbach (eds.), Higher Education: An International Reference. Indiana University Press, 215-223.
21. Njeuma et al. (1999). Reforming a National System of Higher Education: The case of Cameroon. ADEA/WGHE World Bank, Washington DC.

22. Doh, P. S. (2007). Harmonisation Challenges in Higher Education: Case of the French and British Bicultural System in Cameroon. Published M.Phil Thesis, University of Tampere,

23. Ben-David, J. (1977). Centers of Learning: Britain, France, Germany, United States. An Essay prepared for the Carnegie Foundation on Higher Education. New York: McGraw-Hill.

24. Fuller, S. (2005). What Makes Universities Unique? Updating the Ideal for an Entrepreneurial Age. Higher Education Management and Policy, vol.3.

25. Bennis, W. (2009). On Becoming a Leader (Revised Edition). New York: Addison-Wesley Publishing.

26. Black, S. A., \&Copsey, J. A. (2014a). Does Deming's "System of Profound Knowledge" Apply to Leaders of Biodiversity Conservation? Open Journal of Leadership, 3, 53-65.

27. Black, S. A., \&Copsey, J. A. (2014b). Purpose, Process, Knowledge and Dignity in Interdisciplinary Projects. Conservation Biology, 28, 1139-

28. Black, S. A., Groombridge, J. J., \& Jones, C. G. (2011). Leadership and Conservation Effectiveness: Finding a Better Way to Lead. Conservation Letters, 4, 329-339.

29. Busher, H. (2006). Understanding Educational leadership: People, power and culture. New York: Open University Press.

30. Groombridge, J. J., \& Jones, C. G. (2013). Using Better Management Thinking to Improve Conservation Effectiveness. ISRN Biodiversity, 2013, Article ID: 784701.

31. Black, S. A., Meredith, H. M. R., \&Groombridge, J. J. (2011). Biodiversity Conservation: Applying New Criteria to Assess Excellence. Total Quality Management, 22, 1165-1178.

32. Bryman, A. (2007). Effective Leadership in Higher Education: A Literature Review. Studies in Higher Education, 32, 693- 710.

33. Clegg, S., \&McAuley, J. (2005). Conceptualizing Middle Management in Higher Education: A 
International Journal of Trend in Scientific Research and Development (IJTSRD) ISSN: 2456-6470

Multifaceted Discourse. Journal of Higher Education Policy and Management, 27, 9-34,

34. D’Amico, R., Vermigli, P., \&Canetto, S. S. (2011). Publication Productivity and Career Advancement by Female and Male Psychology Faculty: The Case of Italy. Journal of Diversity in Higher Education,

35. Davies, J., Hides, M. T., \& Casey, S. (2001). Leadership in Higher Education. Total Quality Management, 12, 1025-1030, http://dx.doi.org/10.1080/09544120120096197

36. Deem, R. (1998). "New Managerialism" and Higher Education: The Management of Performances and Cultures in Universities in the United Kingdom. International Studies in Sociology of Education, 8, 47-70. http://dx.doi.org/10.1080/0962021980020014

37. Defazio, D., Lockett, A., \& Wright, D. M. (2009). Funding Incentives, Collaborative Dynamics and Scientific Productivity: Evidence from the EU Framework Program. Research Policy, 38, 293305. http://dx.doi.org/10.1016/j.respol.2008.11.008

38. delSordo, C., Orelli, R. L., Padovani, E., \&Gardini, S. (2012). Assessing Global Performance in Universities: An Application of Balanced Scorecard. Procedia-Social eand Behavioral Sciences, 46, 4793-4797. http://dx.doi.org/10.1016/j.sbspro.2012.06.336

39. Deming, W. E. (1982). Out of the Crisis. Cambridge, MA: MIT Center for Advanced Engineering Study. ECU (Equality Challenge Unit) (2015). Athena SWAN Charter. http://www.ecu.ac.uk/equality-chartermarks/athena-swan/

40. Etzkowitz, H., Kemelgor, C., Neuschatz, M., Uzzi, B., \& Alonzo, J. (1994). The Paradox of Critical Mass for Women in Science. Science, 266, $51-54$. http://dx.doi.org/10.1126/science.7939644

41. Garforth, L., \& Kerr, A. (2009). Women and Science: What's the Problem? Social Politics, 16, 379-403. http://dx.doi.org/10.1093/sp/jxp015

42. Gayle, D. J., Tewarie, B., \& White, A. Q. (2003). Governance in the Twenty-First-Century University: Approaches to Effective Leadership and Strategic Management: ASHE-ERIC Higher Education Report. San Francisco, CA:
43. Jossey-Bass. Gibbons, M. (1998). Higher Education Relevance in the 21st Century. Washington DC: World Bank. Goffee, R., \& Jones, G. (2009). Clever: Leading Your Smartest, Most Creative People. Boston, MA: Harvard Business Press.

44. Goleman, D. (1997). Emotional Intelligence. New York: Bantam. Hamel, G. (2009). Moonshots for Management. Harvard Business Review, 87, 9198

45. Gronn, P. (2000). Distributed properties: A new architecture for leadership, Educational Management and Administration, 28(3): 317-38.

46. Harrison, B.T. (1994). Applying critical ethics to educational management, Educational Management and Administration, 22(3): 175-83.

47. Heifetz, R. A., \& Laurie, D. L. (1997). The Work of Leadership. Harvard Business Review, 75, 124134.

48. Hersey, P., \& Blanchard, K. H. (1969). Life Cycle Theory of Leadership. Training Development, 23, 26-34.

49. Herzberg, F. (1976). One More Time: How Do You Motivate Employees? Harvard Business Review, 81, 87-96.

50. Huy, Q. M. (2001). In Praise of Middle Managers. Harvard Business Review, 79, 72-79.

51. Kanter, R. M. (2003). Leadership and the Psychology of Turnarounds. Harvard Business Review, 81, 58-67.

52. Kennedy, C. (1994). Managing with the Gurus. London: Random House.

53. Kotter, J. P. (1996). Leading Change. Boston, MA: Harvard Business School Press.

54. Kouzes, J. M., \& Posner, B. Z. (2007). The Leadership Challenge (4th ed.). San Francisco, CA: Jossey-Bass Publishers.

55. Krantz, J., \& Gilmore, T. N. (1990). The Splitting of Leadership and Management as a Social Defense. Human Relations, 43, 183-204. http://dx.doi.org/10.1177/001872679004300206

56. Liefner, I. (2003). Funding, Resource Allocation, and Performance in Higher Education Systems. Higher Education, 46, 469-489. http://dx.doi.org/10.1023/A:1027381906977 
57. MacBeath, J. and MacDonald, A. (2000). Four dilemmas, three heresies and a matrix, in K.A. Riley and K.S. Louis (eds) Leadership for change and school reform, London: RoutledgeFalmer.

58. Macdonald, J. (1998). Calling a Halt to Mindless Change. New York: American Management Association International.

59. McGregor, D. M. (1957). The Human Side of Enterprise. Management Review, 46, 22-28.

60. Middlehurst, R. (1999). New Realities for Leadership and Governance in Higher Education? Tertiary Education and Management, 5, 307-329. http://dx.doi.org/10.1080/13583883.1999.9966999

61. Middlehurst, R. (2004). Changing Internal Governance: A Discussion of Leadership Roles and Management Structures in UK Universities. Higher Education Quarterly, 58, 258-279. http://dx.doi.org/10.1111/j.1468-

2273.2004.00273.x

62. Mintzberg, H. (2009a). Managing. San Francisco, CA: Berrett-Koehler. Mintzberg, H. (2009b). Rebuilding Companies as Communities. Harvard Business Review, 87, 140-143.

63. Montesinos, P., Carot, J. M., Martinez, J.-M., \& Mora, F. (2008). Third Mission Ranking for World Class Universities: Beyond Teaching and Research. Higher Education in Europe, 33.

64. Muijs, D. and Harris, A. (2003). Teacher Leadership - improvement 15 through empowerment? An overview of the literature, Educational Management and Administration, 31(4): 437-48.

65. Oakland, J. S. (2001). Total Organizational Excellence; Achieving World Class Performance. Oxford: Butterworth-Heinemann. Peters, T., \& Waterman, R. H. (1982). In Search of Excellence. New York:

66. Owens, R. G. (2001). Organizational Behaviour in Education: Instruction Leadership and School Reform. $7^{\text {th }}$ Ed. Boston: Allyn \& Bacon.

67. Harper Row. Robinson, W. L. (1974). Conscious Competency-The Mark of a Competent Instructor. The Personnel Journal-Baltimore, 53, 538-539

68. Rummler, G., \& Bache, A. (1995). Improving Performance: How to Manage the White Space in the Organization Chart. San Francisco, CA: Jossey-Bass.

69. Republic Of Cameroun (1998). Law No 98/004 of $14^{\text {th }}$ April 1998:Orientation Law and Guidelines for Education in Cameroon. Yaounde: SOPECAM.

70. Schofer, E., \& Meyer, J. W. (2005). The Worldwide Expansion of Higher Education in the Twentieth Century. American Sociological Review, 70, 898-920.

71. Sergiovanni, T.J. (1992). Moral Leadership: Getting to the Heart of School improvement, San Francisco, CA: Jossey-Bass.

72. Sergiovanni, T.J. (1992). Moral Leadership: Getting to the Heart of School improvement, San Francisco, CA: Jossey-Bass.

73. Sergiovanni, T.J. (2001). Leadership: What in it for school? London: RoutledgeFalmer.

74. Scholtes, P. R. (1998). The Leader's Handbook: Making Things Happen, Getting Things Done. New York: McGraw Hill. 